JOURNAL DE PHYSIQUE TV

Colloque C2, supplément au Journal de Physique III, Volume 5, février 1995

\title{
Growth and Characterization of Shape Memory Cu-Zn-Al Single Crystals
}

\author{
P. Perin, G. Bourbon*, B.C. Goo*, A. Charai, J. Bernardini and Ch. Lexcellent* \\ Laboratoire de Métallurgie, URA 443, Faculté St. Jérôme, 13397 Marseille cedex 20, France \\ * Laboratoire de Mécanique Appliquée, URA 004, Faculté des Sciences, 25030 Besançon cedex, France
}

\begin{abstract}
To provide a better insight of shape memory alloys (SMA) behavior, $\mathrm{Cu}$ $\mathrm{Zn}$-Al single crystals were grown by the Bridgman technique. Melting was performed under pure argon in a graphite crucible allowing to obtain samples (total length $40 \mathrm{~mm}$ ) with the final shape directly suitable for mechanical tests (cylinders with taper heads: $25 \mathrm{~mm}$ useful length, $4 \mathrm{~mm}$ in diameter). The chemical composition was checked by Differential Scanning Calorimetry and resistivity. It was found that a small zinc concentration gradient exists along the samples: it induces a difference less than $5 \mathrm{~K}$ for transformation temperatures in the useful length.The morphology, the shape deformation, crystal structure, sub-structure and orientation have been investigated by optical, transmission and scanning electron microscopy and by X-Ray diffraction. Pseudoelastic isothermal tensile tests and training under constant applied stress and variable temperatures were carried out. The training efficiency for these elaborated alloys is very large (about $80-90 \%$ ).
\end{abstract}

\section{INTRODUCTION}

A better physical understanding of the complex mechanical behaviour of shape memory alloys during phase transformation needs experiments on single crystals. Therefore, starting from an industrial polycrystalline alloy prepared by "Tréfimétaux Society", we have elaborated and characterized $\mathrm{Cu}-\mathrm{Zn}-\mathrm{Al}$ single crystals. In the present paper we report (i) the method of preparation of samples with a shape directly adapted for ther momechanical tests (ii) the characterization by X Ray diffraction (Lauë method) and Differential Scanning Calorimetry (DSC) analysis in order to check the orientation and the gradient composition respectively (iii) the shape of the isothermal tensile curves and the training efficiency of classical anisothermal cyclic tests performed under a constant applied stress, (iv) a microstructural observation by Transmission Electron Microscopy (TEM) before and after thermomechanical tests.

\section{CRYSTAL GROWTH AND CHARACTERIZATION}

The starting material is an industrial $\mathrm{Cu}-\mathrm{Zn}(25.63 \mathrm{wt} \%)-\mathrm{Al}(4.2 \mathrm{wt})$ polycrystalline alloy without any refinent. DSC measurements gives $\mathrm{M}_{\mathrm{f} 90}=-272 \mathrm{~K}$, 
$\mathrm{M}_{\mathrm{s} 10}=288.5 \mathrm{~K}, \mathrm{~A}_{\mathrm{s} 90}=286.5 \mathrm{~K}$ and $\mathrm{A}_{\mathrm{f} 10}=297 \mathrm{~K}$. Different single crystals are grown in a vertical furnace by the Bridgman method using a graphite crucible sealed in a quartz capsule under pure $N 60$ Argon atmosphere; they present a shape allowing direct tensile tests measurements (usefullength $25 \mathrm{~mm}$, diameter $4 \mathrm{~m} \mathrm{~m}$ with taper heads, cf. Figure 1). The thermal sequence is as follows: (i) increase in te mperature up to $1293 \mathrm{~K}$ which is maintained during one hour, (ii) displacement of the furnace at the optimized rate of $6 \mathrm{~cm} / \mathrm{h}$. untill $1043 \mathrm{~K}$ which is maintained during 0.75 hour, (iii) quench by breaking the quartz capsule by gravity in war $m$ water $(333 \mathrm{~K}, 0.5 \mathrm{~h}$.$) .$

Figure 1

Sche matic representation of the grown crystals

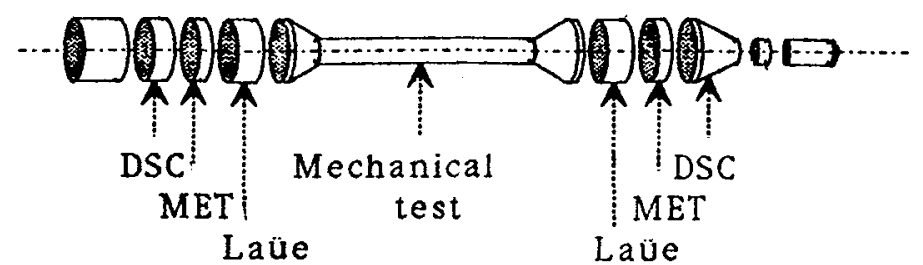

Figure 2

Orientation of the different samples

Before any examination, the crystal is weigthed to evaluate the average loss which is about $0.03 \%$. Then the single crystal state is checked by etching the sample in $\mathrm{HNO}_{3}$. Scanning Electron Microscopy (SEM) analysis reveals the presence only of the austenite phase (A).

The different crystal orientations determinated by the back reflection Laue method are reported on figure 2. The longitudinal axis of the samples which are the elaboration axis present a random orientation.

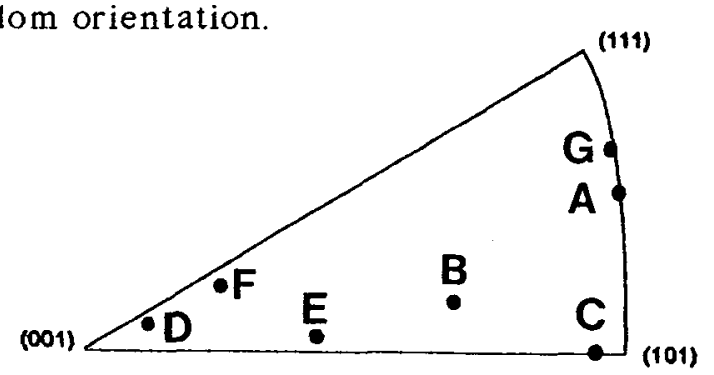

DSC measurements, performed at the positions shown on figure 1 , allow us to obtain the transformation temperatures, $\Delta H_{A \rightarrow M}$ and $\Delta H_{M \rightarrow A}$ enthalpies of transformation. Except three values around $10 \mathrm{~J} / \mathrm{g}$ which are too high, others $\Delta H_{A \rightarrow M},\left(\Delta H_{M \rightarrow A}\right)$ values are in fair agreement with those generally reported in the literature [1]. A variation less than five degrees between the transformation temperature at the useful part borders of the samples is measured [2]. These transformation temperatures, also checked by resistivity measurements [3], are in agree ment with ones obtained by DSC.

\section{THERMOMECHANICAL TENSILE TESTS}

\subsection{Mechanical testing procedure}

Mechanical tests are performed on an INSTRON 6025 machine with capacity of \pm 10 tons. For several single crystals, cyclic loading-unloading tensile tests at a fixed temperature, are performed. The test temperatures are in the pseudoelastic range : $10 \mathrm{~K}<\left(\mathrm{T}-\mathrm{A}_{\mathrm{f}}\right)<50 \mathrm{~K}$. 
Applied stress rates are $0,1 \mathrm{MPa} / \mathrm{s}$ or $1 \mathrm{MPa} / \mathrm{s}$ between stress free state $\sigma=0$ and a sufficient elongation to obtain the complete phase transformation.

Each cyclic test under loading-unloading stress is followed by a pure thermal cyclic test in order to quantify the amplitude of the obtained two-way shape memory effect. Several non-isothermal cyclic tests are performed under a constant loading: The stress applied on the austenitic phase is not large enough to induce the phase transformation at this given temperature. At high test temperatures, the material is in the austenitic state while martensite is present at low temperatures. After such experiments, a cyclic thermal test is performed to check the efficiency of training.

\subsection{Cyclic isothermal tensile tests (first cycle)}

The first cycle of loading-unloading tensile tests carried out at a constant $\sigma$ is shown on figure 3 . On the first loading, one observes the austenite elastic deformation until the applied stress reaches $\sigma_{\mathrm{AM}}^{\mathrm{ap}}$ which is the treshold stress of martensite appearance. Then, the deformation due to $A \rightarrow M$ transition takes place

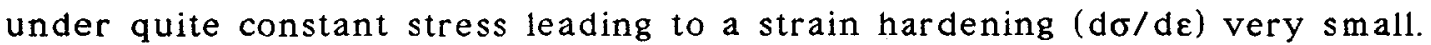
However, it should be pointed out that this strain hardening increases versus the applied stress rate (cf. figure 3 ). The apparent pseudoelastic deformation corresponding to the complete phase transition is called Yapp. When the phase transformation is finished, the stress suddenly increases, this is linked to the elastic behaviour of $M$. When the stress is reversed, the elastic martensitic deformation reverses until $\sigma$ reaches $\sigma_{M A}^{a p}$. The plateau, linked to the opposite transformation ( $M \rightarrow A$ ) is present until the martensite phase ( $M$ ) completely disappears. Then, the A elastic deformation takes place. This type of single crystals behaviour which is strongly dependent on alloy composition and growth modes, was previously obtained by Muller and Xu [4] on $\mathrm{Cu}-\mathrm{Zn}(19.0 \mathrm{Wt}$ ) - Al (7.0 Wt \%).
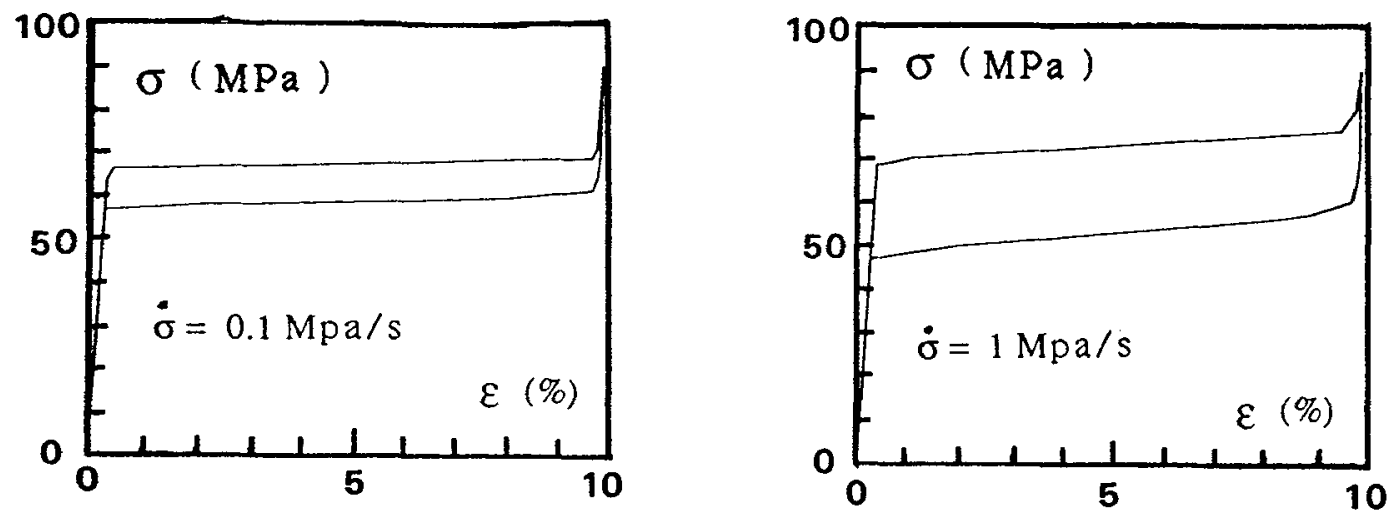

Figure 3: B specimen stress-strain curves, $\mathrm{T}=335 \mathrm{~K}$

The observed plateau was correlated to the growth and propagation of only one variant of martensite, but a great number of interfaces between this variant and the austenite phase was observed and counted by Jiang and $\mathrm{Xu}$ [5]. Generally in $\mathrm{Cu}-\mathrm{Zn}-\mathrm{Al}$ single crystal, habit planes orientations are close to $(110)_{\mathrm{A}}$ and shear directions close to $\langle 110\rangle[6]$. Using the orientation of the samples, the schmid 
factors relative to the different habit planes (twelve cases) can be calculated and one can choose the greatest value leading to the maximum shear stress. The corresponding variant will appear. The schmid factor can be defined by:

$\varphi=\cos \alpha \cos \beta$ where $\alpha$ is the angle between the loading direction and the normal vector to the habit plane and $\beta$ the angle between the loading direction and the shear direction in the habit plane.

Hence, we can calculate the intrinsic treshold shear stress $\sigma_{\mathrm{AM}}^{\circ}\left(\sigma_{\mathrm{MA}}^{\circ}\right)$ which is only dependent on the temperature and on the chosen alloy:

$$
\sigma_{\mathrm{AM}}^{0}=\varphi \sigma_{\mathrm{AM}}^{\mathrm{ap}} \quad\left(\sigma_{\mathrm{MA}}^{\mathrm{o}}=\varphi \sigma_{\mathrm{MA}}^{\mathrm{ap}}\right)
$$

This intrinsic value $\sigma_{\mathrm{AM}}^{\circ}\left(\sigma_{\mathrm{MA}}^{\circ}\right)$ is also linked to the test temperature $\mathrm{T}$ :

$$
\sigma_{A M}^{o}=b_{1}\left(T-M_{s}^{o}\right) \quad\left(\sigma_{M A}^{o}=b_{2}\left(T-A_{s}^{o}\right)\right)
$$

From the present measurements carried out on five single crystals, we obtain for the constant $b_{1}$ and $b_{2}$ the values 0.8 and $0.7 \mathrm{MPa} / \mathrm{K}$ respectively. These values are in fair agreement with those previously reported in the litterature for other $\mathrm{Cu}-\mathrm{Zn}-\mathrm{Al}$ single crystals [7] (1 $\mathrm{MPa} / \mathrm{K})$.

Moreover, despite the fact that the intrinsic shear deformation value $g$ (equal to $\gamma \mathrm{ap} / \varphi$ ) is dependent on the alloy composition, the calculated values are close to those obtained by Guenin [6] and Patoor et al [7] for different $\mathrm{Cu}-\mathrm{Zn}-\mathrm{Al}$ alloys.

Figure 3 shows that the hysteresis width increases with the applied stress rate .

On Cu-Al-Ni single crystals tensile experiments, it has been also observed by Otsuka et al. [8] an increase of the hysteresis width as a function of the applied strain rate. Rodriguez and Brown [9] reported the effect of strain rate on the superelastic loop and explained such a behaviour by the temperature change of the specimen linked to the release of the phase transformation latent heat.

To sum marize, one must develop an "elastoviscoplastic" model adapted to the shape memory alloys to take into account this loading rate effect.

\subsection{Cyclic tests}

On the (A) single crystal, ten tensile cycles followed by a stress free thermal cycle are applied. During the mechanical loading, $\gamma^{a p}$ is about $5 \%$ and the residual strain is negligible (Figure 4). The consecutive thermal cycle for $\sigma=0$ gives a strain equal to $3.8 \%$. However the number of cycles is not large enough to create a new stable internal structure of training defects.

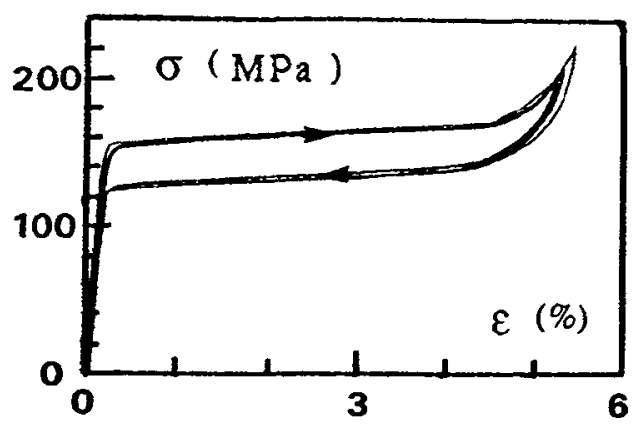

a: (A) specimen, $\mathrm{T}=335 \mathrm{~K}$ $\sigma=1 \mathrm{MPa} / \mathrm{s} ; \mathrm{N}=10$

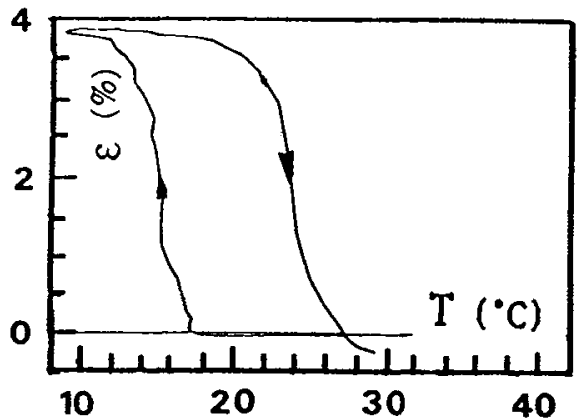

Figure 4:

b: after a, training efficiency $(\sigma=0 \mathrm{MPa})$ 
On the $(\mathrm{H})$ single crystal, ten thermal cycles are achieved under the constant stress $\sigma=70 \mathrm{MPa}$. The specimen being in the austenitic state, at high temperature, then a free stress thermal cycle performed on this sample shows a very high training efficiency $(85 \%)$ (figure 5 ).

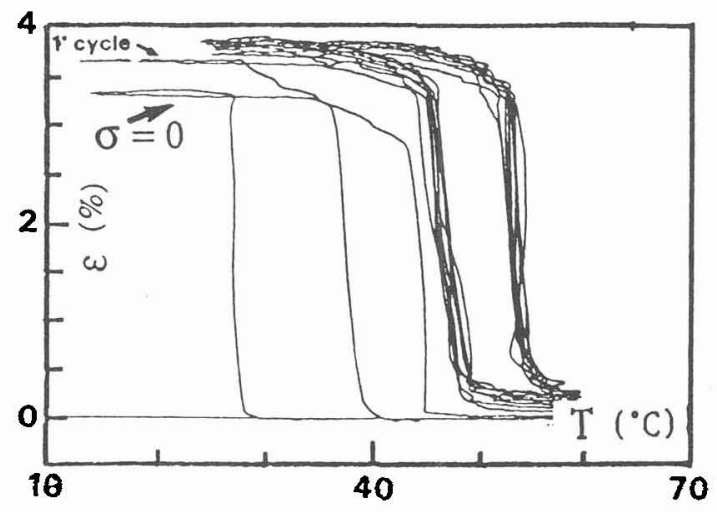

Figure 5: Thermal path on specimen $(\mathrm{H}),(\sigma=70 \mathrm{MPa}, \mathrm{N}=10)-$ Training efficiency obtained for $\sigma=0 \mathrm{MPa}$.

\section{TRANSMISSION ELECTRON.MICROSCOPY CHARACTERIZATION}

In order to relate the mechanical training of this shape memory alloy to the induced defects. Transmission Electron Microscopy observations are performed in the same conditions before and after the thermomechanical loading. Investigations are made by using a Philips EM 400T TEM/STEM microscope operating at $100 \mathrm{kV}$. One critical step is the TEM samples preparation which need a particular care because of the possible artefacts that can be introduced during the thining. The samples $(3 \mathrm{~mm}$ in diameter and less than $100 \mathrm{~nm}$ in thickness) are obtained by electrolytic thining method. Details of experimental conditions can be found in reference [2].

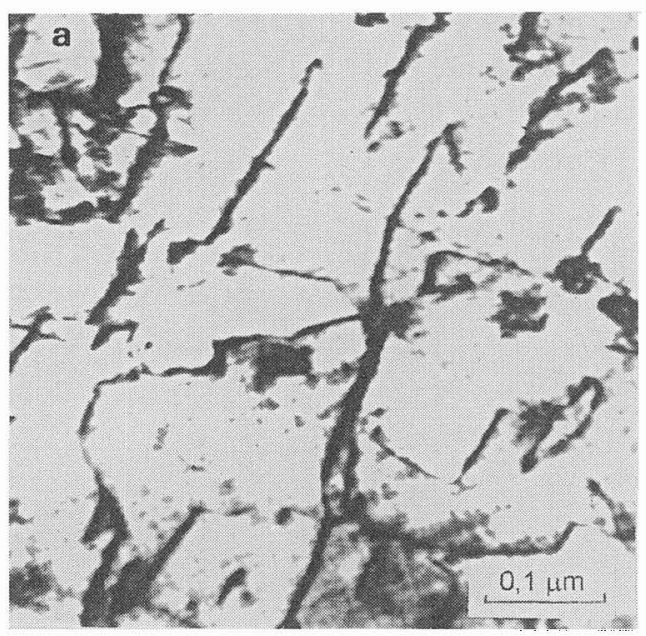

Figure 6: Dislocation network in Austenite after ther momechanical loading (sample B)

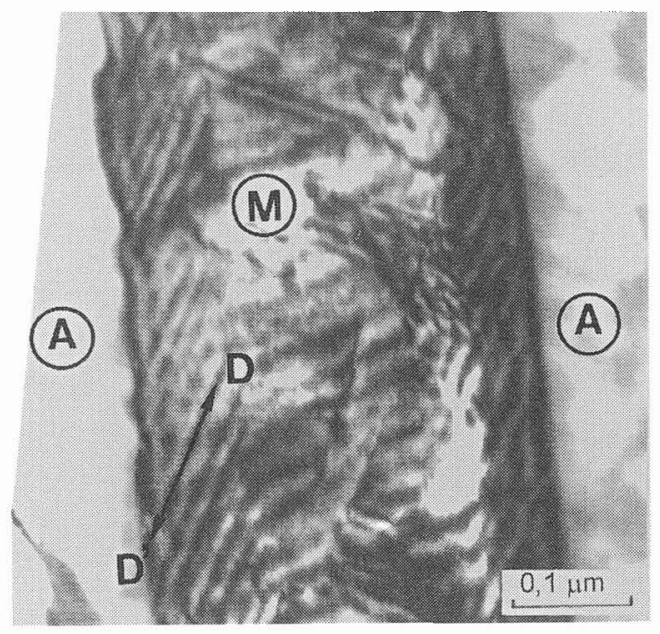

figure 7: Interfacial dislocations after ther momechanical loading (sample B) 
For the as prepared alloys, we observe just after the betatization thermal treatment the expected microstructure and no clear evidence for the existence of defects such as dislocations in the austenitic phase. However few antiphase boundaries and interfacial dislocations between $A$ and $M$ are observed.

After the mechanical training (sample (B), isothermal cyclic $T=335 \mathrm{~K}, \sigma=1 \mathrm{MPa}$ /s, $\mathrm{N}=25$ ), one major change in the microstructure is observed: evidence of bulk dislocations in the A austenite phase (Figure 6). Moreover interfacial dislocations regularly distributed between $A$ and $M$ are clearly visible (Figure7). At this stage, we believe that the training effect could be related to these interfacial dislocations located between the preferential Martensite variant (created by the stress orientation) and Austenite.

\section{CONCLUSION}

Massive single crystals of $\mathrm{Cu}-\mathrm{Zn}-\mathrm{Al}$ have been obtained by the Bridgman method with a suitable shape for mechanical tests. DSC and Laue characterization allowed to determine their transformation temperatures and their orientations respectively. Loading - unloading tests have revealed the intrinsic behaviour of these single crystals (whatever their orientation) with a not negligible effect of the stress rate. An increase of bulk dislocation density is observed by TEM after isothermal training effect.

\section{REFERENCES}

[1] Hsu T.Y., Zuzyo A.O, Zhol X.W, Humbeeck J.V and Delaey L.,

Scripta Met. Mater. 25 (1991) 165-166.

[2] Perin P., Mémoire Ingenieur C.N.A.M., Aix- En- Provence, France, (1994).

[3] Vacher P. and Lexcellent Ch., Rev. Phys. Appl. 25 (1990) 783-797.

[4] Muller I. and Xu H.,. Acta Met. Mater.39 (1991) 263-271.

[5] Jiang Q. and Xu H., Acta Met. Mater.40 (1992) 607-613.

[6] Guenin G., Doctorat thesis, $N^{\circ} 37510$ INSA Lyon France (1979).

[7] Patoor E., Eberhadt A.and Berveiller M., Acta Met. 35 (1987) 2779-2789.

[8] Otsuka K., Wayman C.M., Nakai K., Sakamoto H. and Shimizu K., Acta Met. 24 (1976) 207-226.

[9] Rodriguez C. and Brown L., Shape memory effects in alloys (Plenum Press NY, USA 1975) pp. 29-48. 